\title{
Ocean Hemisphere Geomagnetic Network: its instrumental design and perspective for long-term geomagnetic observations in the Pacific
}

\author{
Hisayoshi Shimizu and Hisashi Utada \\ Earthquake Research Institute, University of Tokyo, Yayoi 1-1-1, Bunkyo-ku, Tokyo 113-0032, Japan \\ (Received May 21, 1999; Revised August 17, 1999; Accepted August 30, 1999)
}

\begin{abstract}
Geomagnetic field observations are planned and started in the Ocean Hemisphere Network Project. A new magnetometer system suitable for on-land long-term observations in remote places in the Pacific area are designed. Performance and characteristics of the magnetometers are examined through test observations, which revealed that magnetic field variation due to temperature change of the fluxgate sensor unit is the major cause for inaccuracy in three components. Analysis of test observation data indicated that the temperature induced variations can be removed using a simple two-coefficient filter. A conservative expectation of absolute accuracy is $10 \mathrm{nT}$ or less if proper temperature correction and once-a-year absolute measurement at each OHP station are carried out. Distributions of the OHP geomagnetic stations to obtain better geomagnetic field model are examined. It was found that establishing about 10 geomagnetic stations in the Pacific will greatly improve the geomagnetic field models, and will facilitate the study of geomagnetic field distribution and variation in the Pacific. The concept of the design of the OHP magnetometer system may be applied to long-term ocean bottom magnetic observation, which is another way to cover the Earth by geomagnetic stations.
\end{abstract}

\section{Introduction}

Geomagnetic field data provide us unique and direct information on the magnetohydrodynamics in the earth's outer core. The deep electrical conductivity structure in the mantle can be determined by using the relationship between the external and internal parts of geomagnetic field variations through geomagnetic induction (Banks, 1969; Achache et al., 1981). Only long-term, continuous, and stable geomagnetic observatories can afford data for these kinds of investigations. In these studies, distribution of global geomagnetic observatories directly affects the quality of analyses. Spatially uniform and dense network of geomagnetic observatories is necessary to have an accurate estimation of spherical harmonic coefficients, which is employed for many of global scale geomagnetic field analyses (Langel, 1987). A number of workers have pointed out the difficulties due to the uneven distribution of observatories between the northern and southern hemispheres, between the land and ocean areas, and so on, for many years (e.g., Langel et al., 1995). This paper aims to discuss one of the possible approaches to attain better configuration of geomagnetic observatory network.

The Ocean Hemisphere Network Project (OHP) is a Japanese five-year project to construct a network of geophysical observatories consisting of seismic, geodetic and geomagnetic components to carry out long-term observations in the hemisphere centered by the Pacific. The OHP aims to obtain a new image of the earth's deep interior by filling the large gap of geophysical observations in the Pacific (Fukao, 1997; also, special issue of Earth Planets and Space,

Copy right $(\mathrm{C}$ The Society of Geomagnetism and Earth, Planetary and Space Sciences (SGEPSS); The Seismological Society of Japan; The Volcanological Society of Japan; The Geodetic Society of Japan; The Japanese Society for Planetary Sciences. vol. 50, Nos. 11-12, 1998). The electromagnetic component of the OHP is composed of three major elements; development of ocean bottom geomagnetic observatory system (Toh et al., 1998), long-term geomagnetic observations on land, and observation of the earth's electric field by using a submarine cable network (Shimizu et al., 1998). Major concern of this paper is paid to the geomagnetic observations on land. Although ocean bottom observatory is undoubtedly needed, observatory distribution will be greatly improved by installing magnetometers on islands in the Pacific.

Our effort may be comparable to INTERMAGNET (1994) in a sense. However, the magnetometer system that we are going to install is designed based on a different concept from that of INTERMAGNET. As shown in Section 2, the system is highly automated.

Magnetic field data taken at OHP geomagnetic stations will be open to public starting year 2,000. The data will be stored in HD in the Earthquake Research Institute, University of Tokyo, and anyone will be able to access the data via internet. Observations at the OHP geomagnetic stations will be continued at least five years after the OHP finishes. Moreover, it is planned to keep operating the stations for much longer time, say, more than ten years, to enable us to discuss short term secular variations in the Pacific region although secular variation is believed to be rather low in the region (e.g., Bloxham and Gubbins, 1985).

This paper tries to answer the question to what extent the OHP geomagnetic observatory in the Pacific islands improves our knowledge on the spatial and temporal characteristics of the geomagnetic field in the region, supposing that continuous data are obtained for decades of period. Performance of the magnetometer system used in the OHP will be 


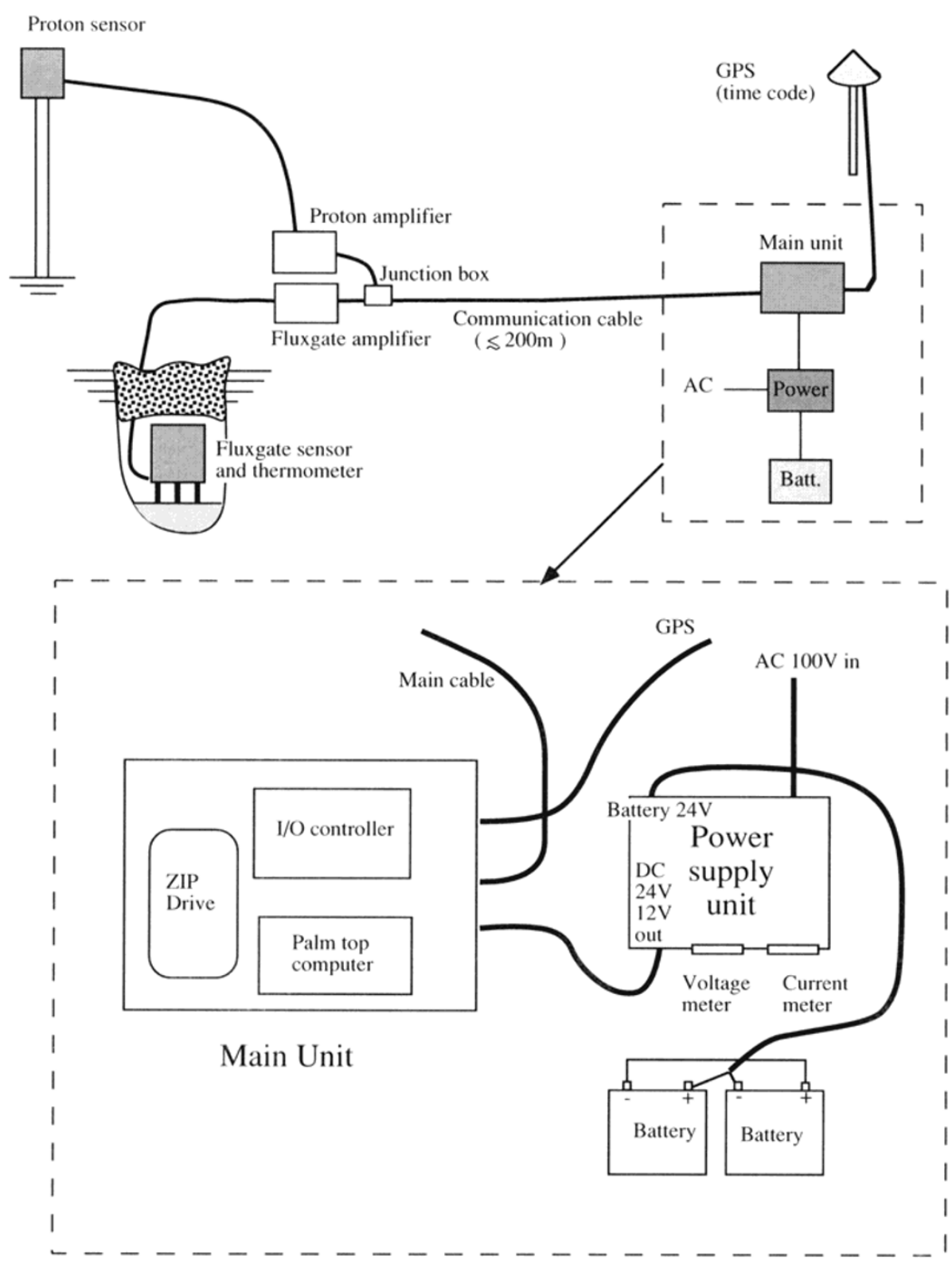

Fig. 1. Configuration of the OHP magnetometer system (above) and description of the main and power supply units (below). The geomagnetic total intensity is measured by a proton magnetometer. Its sensor is mounted on an aluminum pillar at about $2 \mathrm{~m}$ above the ground level. Measurement is done every minute. Geomagnetic three components are measured by a fluxgate magnetometer. Its sensor is buried about $1 \mathrm{~m}$ deep in the soil to avoid severe temperature variations. Measurement is done every second. Both total intensity and three component signal are transmitted to the main unit. Main and power supply units should be installed in a building.

described in Sections 2 and 3. Descriptions of characteristics of the magnetometer itself (resolution, precision, frequency response, etc.) are not enough for the present purpose because other factors (easiness of operation, simple configuration of the circuits, mechanical toughness, and so on) are thought to be equally or more important to maintain a longterm array observation. After considering all the possible factors, the final design was determined to be a combination of a proton magnetometer to measure the total intensity and a fluxgate magnetometer to measure time variation of the three components as will be described in the following section. Since temperature variation is regarded as the dominant factor for baseline drift of the fluxgate magnetometer, we tried to parameterize the effect and to find a method of quantitative correction. In Section 4, we attempt to decide an ideal site distribution to be installed during the project years. A simple numerical experiment will be made to show how it improves the model of the geomagnetic field and its time variation in the Pacific by adding data from the OHP sites, if such a site distribution is realized. Summary and discussion are given in Section 5.

\section{System Configuration of the OHP Magnetome- ter}

Figure 1 shows the configuration of a magnetometer system used in the OHP, hereafter referred to the OHP magnetometer. This system enables us to measure long-term variation of the three-component geomagnetic field together 
Table 1. Comparison of standards for three geomagnetic network projects.

\begin{tabular}{|c|c|c|c|}
\hline & INTERMAGNET & $210 \mathrm{MM}$ & OHP \\
\hline \multicolumn{4}{|c|}{ Scalar Magnetometer } \\
\hline Resolution & $0.1 \mathrm{nT}$ & - & $0.1 \mathrm{nT}$ \\
\hline Accuracy & $1 \mathrm{nT}$ & - & $1 \mathrm{nT}$ \\
\hline Range & not specified & - & $25,000-65,000 \mathrm{nT}$ \\
\hline Sampling interval & $30 \mathrm{sec}$ & - & $1 \mathrm{~min}$ \\
\hline \multicolumn{4}{|c|}{ Vector magnetometer } \\
\hline Sensor type & Fluxgate & Fluxgate & Fluxgate \\
\hline Sensor mount & Rigid & Rigid & Gimbals \\
\hline Resolution & $0.1 \mathrm{nT}$ & $0.01 \mathrm{nT}$ & $0.01 \mathrm{nT}$ \\
\hline Dynamic range & $\pm 2,000 \mathrm{nT}$ & $\pm 2,000 \mathrm{nT}$ & $\pm 65,000 \mathrm{nT}$ \\
\hline Bandpass & $\mathrm{DC}-0.1 \mathrm{~Hz}$ & $\mathrm{DC}-1 \mathrm{~Hz}$ & $\mathrm{DC}-1 \mathrm{~Hz}$ \\
\hline Sampling interval & $5 \sec (1 \mathrm{~min})$ & $1 \mathrm{sec}$ & $1 \mathrm{sec}$ \\
\hline Thermal stability & $0.25 \mathrm{nT} / \mathrm{deg}$ & not specified & to be estimated \\
\hline Longterm stability & $5 \mathrm{nT} /$ year & not specified & to be estimated \\
\hline Baseline control & $>1$ point/week & no & $\sim 1$ point/year \\
\hline Accuracy & $5 \mathrm{nT}$ & not specified & to be estimated \\
\hline \multicolumn{4}{|l|}{ Clock } \\
\hline Accuracy & $5 \mathrm{sec} / \mathrm{month}$ & <1 msec (GPS) & $<1 \mathrm{msec}(\mathrm{GPS})$ \\
\hline
\end{tabular}

with the total intensity, as well as short-period fluctuations such as the geomagnetic micropulsations. As shown in Table 1 , specification of this magnetometer satisfies most of the requirements involved in the INTERMAGNET standard, which aims baseline controlled geomagnetic observations. It is also compatible with the magnetometer used in the 210 MM (Yumoto et al., 1996) that is a global array to measure the rapid changes in three components.

The system consists of a proton magnetometer, a 3-component fluxgate magnetometer, a controlling and recording units, a power supply unit, and a GPS clock (Fig. 1). The proton magnetometer measures the geomagnetic total intensity every minute with a resolution $0.1 \mathrm{nT}$, while the fluxgate magnetometer measures three components every second with a resolution $0.01 \mathrm{nT}$. Controlled by a palm-top computer, the observed values are recorded in a ZIP disk of $100 \mathrm{MB}$ capacity. The computer is also equipped with an output either by RS232-C or by Ethernet so that on-line telemetry is possible. The clock signal is always synchronized to the GPS signal within an accuracy of $1 \mathrm{msec}$. As shown in Fig. 1, the measuring and controlling units are connected by a communication cable. The analog circuits are built in a water proof container so that they can be either put on the ground or buried in the soil. The communication cable can be extended as long as $200 \mathrm{~m}$, which enables us to put the measuring units sufficiently away from the possible noise sources.
The whole system is fed by an AC power supply unit with a backup by two $12 \mathrm{~V}$ car batteries. If each battery has capacity of $30 \mathrm{Ah}$, the power unit can supply for more than 24 hours in case of an AC power break. In case of longer power breaks, the measurement will be temporarily terminated until recovery of the AC power. The measurement automatically restarts when the AC power is recovered, and no manual operations nor adjustments are needed even for clock, as it is synchronized to the GPS signal. Manual operation is necessary only at the time of changing disks. This is a simple key operation so that the system can be maintained even by a person without a high technical background. Each $100 \mathrm{MB}$ Zip disk can record about 50 days of data.

So far as the observation of rapid variations is concerned, there seem to be no significant problems to be discussed here. In contrast, we have to pay the most attention to the baseline drift in three components to make discussions of slow variations of geomagnetic field possible. The INTERMAGNET standard requires an absolute measurement every week to control each baseline. However, it is not realistic to require such a routine work in the OHP. Instead of doing frequent absolute measurements for the baseline control, we tried to minimize the drift of the fluxgate magnetometer by better designing of the instrument, so that once-a-year absolute measurement is sufficient to sustain the absolute accuracy of the observation. 
Absolute measurements at the OHP stations are/will be made in a similar manner employed by a number of magnetic observatories. Total intensity is measured using proton magnetometer, and declination and inclination are observed using fluxgate theodolite (e.g., Forbes, 1987). Baseline values of horizontal intensity, declination, and vertical component are determined comparing the result of the absolute measurements and output of fluxgate magnetometer during the absolute measurement.

The baseline drift is generally supposed to be due to two major causes, i.e., temperature change of fluxgate sensor and a tilting of the sensor basement. Therefore the sensor is designed to be buried about one meter deep in the soil to suppress the temperature change, and the three-axis fluxgate sensor is mounted on gimbals so that gradual tilting of the sensor basement does not cause a drift. As shown in the next section, soil of $1 \mathrm{~m}$ thick can insulate the daily temperature change, but changes of longer time scales will cause a longterm drift. In order to correct such a drift, temperature of the sensor unit is measured with a thermometer, with resolution $0.01^{\circ} \mathrm{C}$, in the sensor container. In the next section, we will present a result of test measurement to determine the temperature coefficients of three components of the OHP magnetometers.

\section{Temperature Dependence of the Fluxgate Sensor and Expected Absolute Accuracy of the OHP Magnetometers}

The magnetic field values measured using fluxgate magnetometer systems are usually affected by the environmental temperature (e.g., Trigg et al., 1971; Forbes, 1987). Appropriate temperature corrections to the measured magnetic field components are essential to achieve and sustain high absolute accuracy (say, within several nT) of the vector observations. In this section, temperature dependence of the magnetic field measured using the OHP magnetometer systems is examined. Possible temperature correction filters for each component of the OHP magnetometer system will be presented, and performance of the filters is discussed.

Before installation at remote stations, OHP magnetometers are tested at Kakioka Magnetic Observatory (KMO), Japan Meteorological Agency. Test data of four OHP magnetometers, \#2 (now at Kiritimati, Kiribati), \#3 (now at Huancayo, Peru), \#4 (still at KMO) and \#5 (now at Changchun, China) were analyzed with a reference to on site definite (corrected) geomagnetic field data at KMO. Because the locations of the sensors of OHP magnetometers and standard magnetometers of KMO were not the same but about $50 \mathrm{~m}$ apart (Fig. 2), absolute values of the magnetic field are not exactly the same. However, it is expected that the time variations of the "true" magnetic field are regarded as the same within this spatial scale. Therefore, differences of KMO definite field and OHP magnetometer data will be able to isolate the amount of correction for the OHP magnetometer data.

The comparisons of magnetic field components must be made in the coordinate system of the OHP fluxgate magnetometer to examine the temperature dependence of each sensor. KMO definite magnetic field data, which are horizontal intensity, declination, and downward intensity are

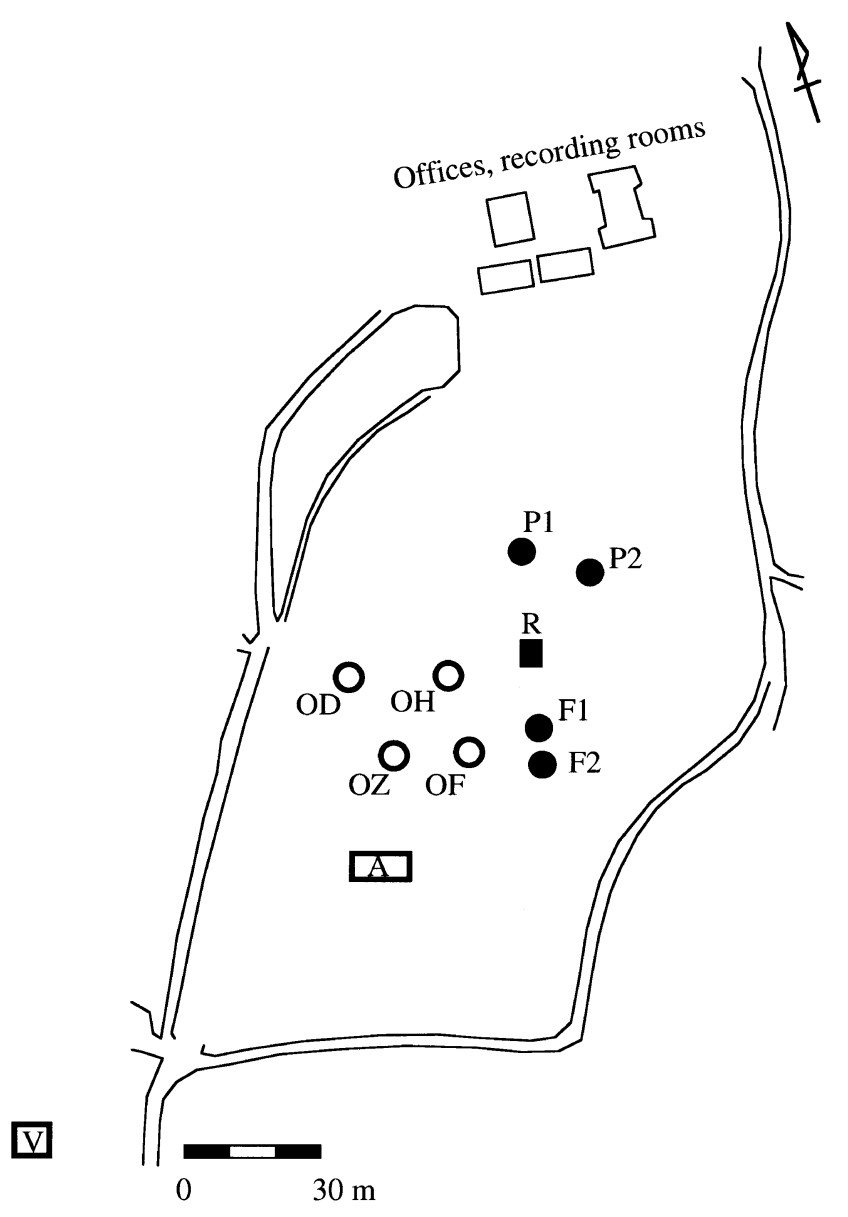

Fig. 2. Arrangement of sensors for the magnetometer tests at KMO. The proton magnetometer sensor was placed either at P1 (for \#2 and \#4) or at P2 (for \#3 and \#5), and the fluxgate sensor at F1 (for \#2 and \#4) or at F2 (for \#3 and \#5). The recording and power supply units were put in a hut $\mathrm{R}$. OH, OD, OZ and $\mathrm{OF}$ are the locations of the sensors of the vector and scalar Overhauser magnetometers, and $\mathrm{V}$ is the location of the 3-component fluxgate variometer. Absolute measurement is done at A.

transformed to the components in fluxgate magnetometer coordinate system, i.e., geomagnetic north-south $\left[\equiv H_{x}(\mathrm{nT})\right]$, east-west $\left[\equiv H_{y}(\mathrm{nT})\right]$ and vertical (downward) $\left[\equiv H_{z}(\mathrm{nT})\right]$ components. The coordinate transformation was done by assuming the direction of the $H_{x}$ sensor is 7.00 degree westward from geographical north, which is the average declination of KMO data during September to December of 1997. Now, the differences in each sensor direction are written simply as

$$
d H_{i}(t)=H_{i}^{\mathrm{OHP}}(t)-H_{i}^{\mathrm{KMO}}(t), \quad(i=x, y, z)
$$

where $H_{i}^{\mathrm{OHP}}$ and $H_{i}^{\mathrm{KMO}}$ are the magnetic field components measured using OHP magnetometer and those calculated from KMO definite magnetic field, respectively. $d H_{i}$ is the amount of correction for each component of the observed OHP magnetometer data. As shown later, the variation part of $d H_{i}$ is mostly due to the temperature variation of the sensor unit.

Test for each magnetometer was conducted in two stages. Large and relatively short time scale temperature variations are applied to the fluxgate sensors in the first stage. This was accomplished by installing the fluxgate sensors on the ground and open to the air (i.e., uncovered by the soil) so that the 

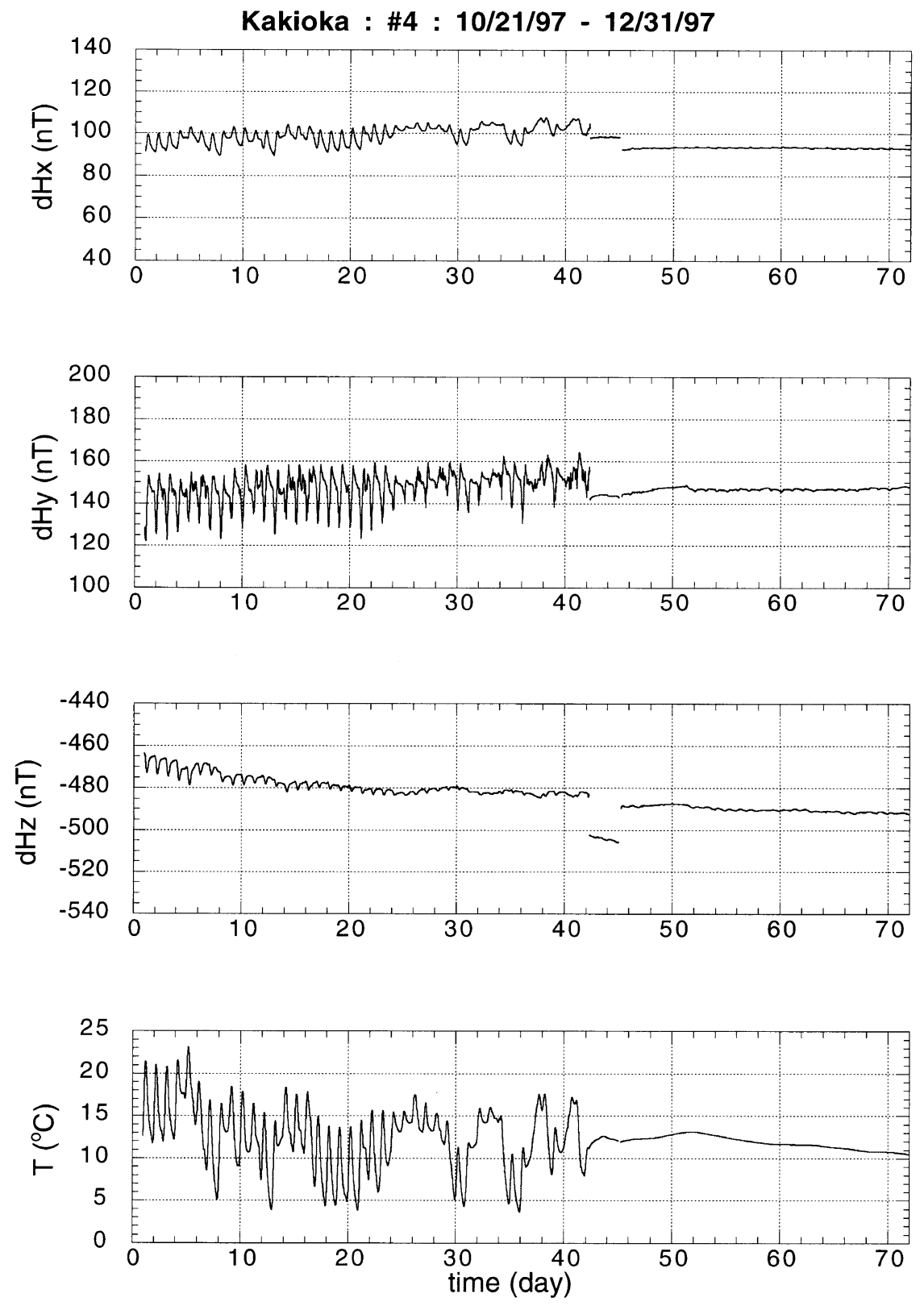

Fig. 3. Differences of the magnetic field data taken by OHP magnetometer \#4 and those by Kakioka Magnetic observatory in the fluxgate magnetometer coordinate from October 21 to December 31, 1997. The fluxgate sensor was buried on day 41.

temperature of the sensors was almost the same as the outside air temperature. Note that other atmospheric effects such as wind or humidity do not cause variation of fluxgate response; the sensor unit was installed on the base of $1 \mathrm{~m}$ deep hole and the sensor is in a closed container. After several days to weeks, the second stage of the experiments were started by burying the sensor unit to insulate from temperature variation as much as possible, as is done at OHP geomagnetic stations. Both stage 1 and 2 data are used to examine temperature dependence of $d H_{i}$ including time scale dependence. Longterm stability of the sensor was also tested for \#4: the second stage of the test has been continued for more than a year. See Table 2 for duration of the stages in each test.

Figure 3 shows the differences in each component, $d H_{x}$, $d H_{y}, d H_{z}$ (all in nT) and temperature of the sensor unit $T$ (in ${ }^{\circ} \mathrm{C}$ ), taken by using magnetometer \#4 during October
Table 2. Duration of test observations in Kakioka.

\begin{tabular}{cccc}
\hline & Now at & First stage & Second stage \\
\hline$\# 2$ & Kiritimati Island & 21 days & 6 days \\
$\# 3$ & Huancayo & 11 days & 9 days \\
$\# 4$ & (Kakioka) & 42 days & 424 days \\
$\# 5$ & Changchun & 53 days & 115 days \\
\hline
\end{tabular}

20 to December 31, 1997. Thirty-minute average values calculated from one-minute values of $d H_{i}$ are plotted. The first stage is until day 41 and the sensor was buried later on the day to start the measurement in the second stage. Insulation of temperature by a layer of soil is evident by tremendously 

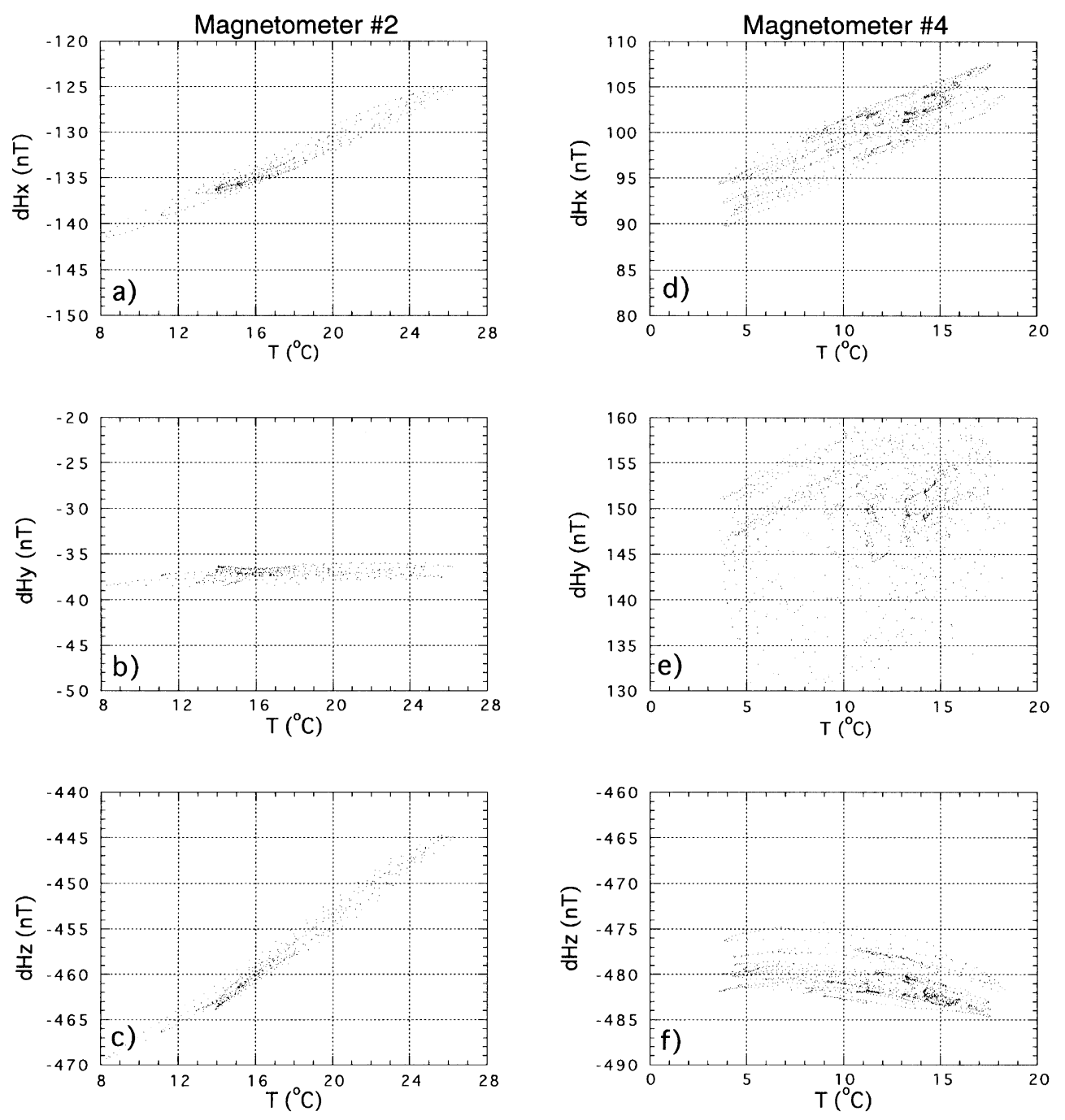

Fig. 4. $d H_{i}-T$ diagrams for OHP magnetometer \#2 ((a), (b), and (c)) and \#4 ((d), (e), and (f)) during the first stage.

reduced temperature variation in the second stage compared with that in the first stage. Correspondingly, the amplitudes of variation of $d H_{i}$ 's are reduced by the insulation. This adduces evidence for the former statement that the most part of time variation of $d H_{i}$ is caused by temperature variation of the sensor unit.

Large daily variation of $d H_{x}$, of order 10-15 nT, highly coherent with temperature variation is seen in the first stage (Fig. 3). However, variation of longer time-scale in $d H_{x}$ is not very evident though it certainly exists in temperature variation. On the contrary, variation of $d H_{z}$ is coherent with that of $T$ in long time-scale but daily variations of them are different from each other. No clear dependence of $d H_{y}$ on $T$ is seen although amplitude of daily variation of $d H_{y}$ is rather large. Each sensor seems to have own temperature dependences both in amplitude and time-scale (i.e., frequency response). Similar characteristics can be seen in the data in the second stage, i.e., little variation is seen in $d H_{x}$ though the sensor is sensitive to the daily variation of temperature, and we may identify variation of $d H_{y}$ and $d H_{z}$ corresponding to long time scale temperature variation (see a bend around day 51).
Temperature dependence of $d H_{i}$ may be extracted more clearly by examining $d H_{i}-T$ diagrams shown in Figs. 4 (stage 1) and 5 (stage 2). Some components of stage 1 data show complicated temperature dependences. On the contrary, stage 2 data show relatively simple tendency of temperature dependency. The differences are due to variety of time-scales contained in the data in each stage.

Designing a general filter which can explain $d H_{i}-T$ relationship for all time-scales may be possible. However, such a filter will surely become complicated requiring many terms (i.e., parameters) so that its application to real data will not be very practical. Test of stage 1 is intended for a correction of temperature variation effects in estimating the inductive response functions of $\mathrm{Sq}$ or other long period geomagnetic variations of external origin to study the upper mantle structure. However, we found that it is unnecessary as the temperature change of the time scale can be sufficiently reduced by insulation of soil (see Fig. 3). Therefore, practically, it will be sufficient if temperature correction filter can reproduce the characteristics of variations of $d H_{i}$ in stage 2 , especially for long time-scales. 

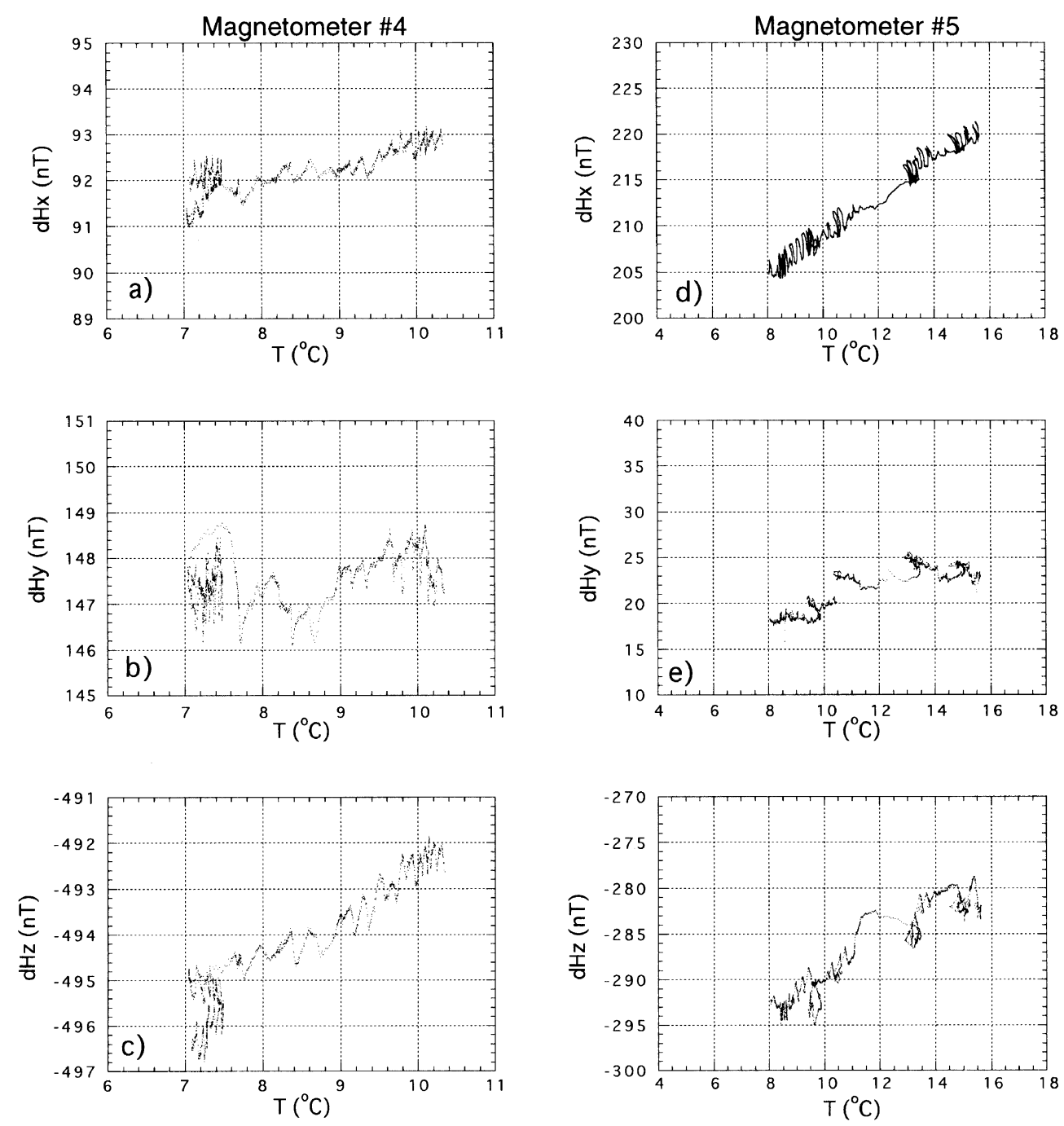

Fig. 5. $d H_{i}-T$ diagrams for OHP magnetometer \#4 ((a), (b), and (c)) and \#5 ((d), (e), and (f)) during the second stage.

It turned out that simple correction formula

$$
d H_{i}(t)=a T(t)+b, \quad(i=x, y, z)
$$

where $a$ and $b$ are coefficients to be determined by stage 2 data, is sufficient to make temperature corrections with accuracy within a few nano-Teslas as shown below. The coefficients may not be applicable for the stage one data because the characteristic time scales of variations are different for the two stages.

The coefficients $a$ (temperature coefficient) and $b$ of (2) for each sensor are determined using the 30-minute average of stage 2 data by a least squares method. The results are summarized in Table 3. $b$ 's are not shown in Table 3 because they correspond to the absolute values (also, they may depend on the soil type or depth of burial) and are only applicable for the test experiment at KMO. Actual b's used for real temperature corrections should be determined by a baselinemeasurements (absolute measurements) after installing the magnetometers at OHP geomagnetic stations.

The temperature coefficients calculated using the stage 1 data of \#2 are also shown because the duration of stage 2 for this instrument is short, only a few days, which is not long enough to determine the temperature coefficients accurately.
Overall, fitting with standard deviation of order less than one nT is possible for all the sensors except one, $H_{z}$ component of \#5. The temperature coefficients are from almost zero to $2.7 \mathrm{nT} /{ }^{\circ} \mathrm{C}$, and necessary temperature correction could amount to $15 \mathrm{nT}$ with temperature variation of about $5^{\circ} \mathrm{C}$, which is typical yearly variation of sensor temperature recorded at Kiritimati and Huancayo (Fig. 6).

Now, we are going to test applicability of the temperature coefficients thus determined. Long-term experiment of OHP magnetometer \#4 has been continued at Kakioka for this purpose. $d H_{i}$ 's from Jan. 1 to Dec. 31, 1998 are plotted in Fig. 7. There are several occasional steps simultaneously in all of the components due to earthquakes near Kakioka. Nevertheless, it was found that no clear changes in temperature coefficients are seen and the gradient is very stable in $d H_{z}-T$ diagram (Fig. 7). After correcting the steps, standard deviations of $d H_{x}$ and $d H_{y}$ became less than $1 \mathrm{nT}$. Therefore, no temperature corrections are necessary for the two components. This is compatible with relatively small temperature coefficients for the two components (see Table 3). However, it is evident that correction for $H_{z}$ is definitely necessary.

Temperature correction for $H_{z}$ component is done using 
Table 3. Temperature coefficients $a$ calculated using test observation data. Correlation coefficient $R$, standard deviation of misfit $\sigma$, minimum and maximum values of misfit are also shown. The values of $a$ and $R$ are not shown when $R$ is less than 0.5 and $a$ is less than 0.2 . $\sigma$, min, and max (all in nT) for corresponding components are from raw (non-corrected) data.

\begin{tabular}{|c|c|c|c|c|c|c|}
\hline & Component & $a$ & $R$ & $\sigma$ & Min & $\operatorname{Max}$ \\
\hline$\# 2$ & $H_{x}$ & 0.92969 & 0.98005 & 0.70 & -1.72 & 1.30 \\
\hline \multirow[t]{2}{*}{ stage 1} & $H_{y}$ & - & - & 0.55 & -0.94 & 1.39 \\
\hline & $H_{z}$ & 1.4899 & 0.98837 & 0.85 & -2.01 & 1.72 \\
\hline$\# 2$ & $H_{x}$ & 2.2693 & 0.85990 & 0.29 & -0.42 & 0.65 \\
\hline \multirow[t]{2}{*}{ stage 2} & $H_{y}$ & - & - & 0.23 & -0.44 & 1.14 \\
\hline & $H_{z}$ & 2.5598 & 0.91993 & 0.24 & -0.38 & 0.61 \\
\hline$\# 3$ & $H_{x}$ & 1.1135 & 0.95827 & 0.30 & -0.70 & 0.87 \\
\hline \multirow[t]{2}{*}{ stage 2} & $H_{y}$ & 2.6744 & 0.98207 & 0.45 & -1.28 & 1.12 \\
\hline & $H_{z}$ & 2.3087 & 0.96240 & 0.58 & -1.14 & 1.49 \\
\hline$\# 4$ & $H_{x}$ & 0.32375 & 0.81178 & 0.27 & -0.78 & 0.68 \\
\hline \multirow[t]{2}{*}{ stage 2} & $H_{y}$ & - & - & 0.49 & -1.41 & 1.93 \\
\hline & $H_{z}$ & 1.1229 & 0.95025 & 0.42 & -1.39 & 1.08 \\
\hline$\# 4$ & $H_{x}$ & 0.29352 & 0.53904 & 0.36 & -0.86 & 0.86 \\
\hline \multirow[t]{2}{*}{ stage 2} & $H_{y}$ & - & - & 0.64 & -1.68 & 1.72 \\
\hline & $H_{z}$ & 0.81734 & 0.90213 & 0.31 & -0.77 & 0.88 \\
\hline$\# 5$ & $H_{x}$ & 2.0485 & 0.98927 & 0.76 & -2.79 & 1.36 \\
\hline \multirow[t]{2}{*}{ stage 2} & $H_{y}$ & 0.43483 & 0.78940 & 0.85 & -3.70 & 1.72 \\
\hline & $H_{z}$ & 1.7797 & 0.94091 & 1.61 & -4.73 & 4.19 \\
\hline
\end{tabular}
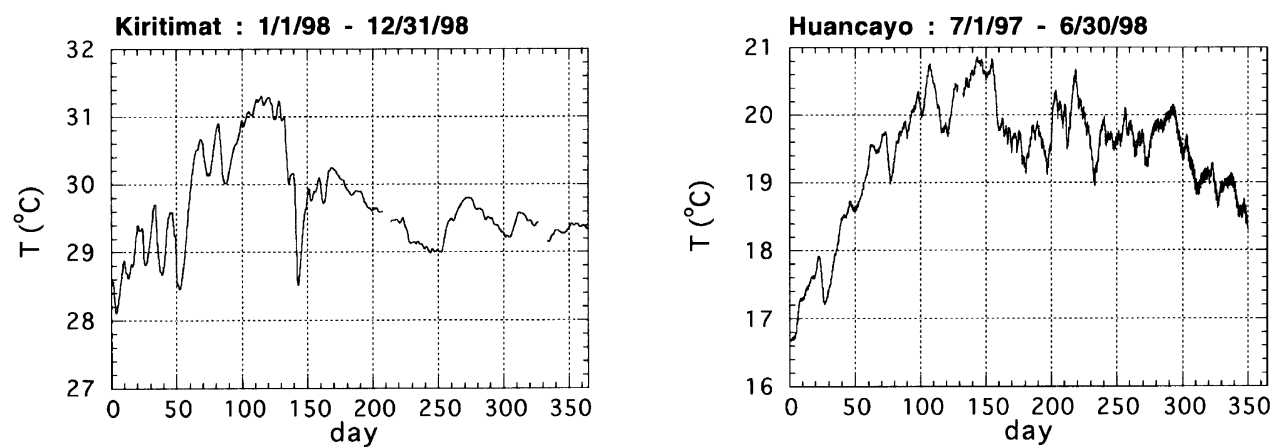

Fig. 6. Observed temperature variations of the sensor units of the OHP magnetometers installed at Kiritimati (\#2) and Huancayo (\#3).

temperature coefficients listed in Table 3. Two sets of coefficients, determined using different portion of data, are listed and both are used. The values of $b$ 's are indeterminate in general, until absolute measurements are done. In this test example, they were determined by assuming zero misfit on Jan. 1, 1998. Now, the calculated correction formulae are

$$
d H_{z}=1.112 \cdot T-504.58
$$

for filter 1 and

$$
d H_{z}=0.817 \cdot T-501.41
$$

for filter 2. Resulting performance of the correction formulae is shown in Fig. 8 (note that steps are removed). Both filters can reproduce the overall tendency of the behavior of $d H_{z}$. Especially, filter 1 could predict $d H_{z}$ very well: average of misfit is less than $0.1 \mathrm{nT}$ and standard deviation is $0.9 \mathrm{nT}$. The misfit of filter 2 is rather large but still tolerable: average is $-1.7 \mathrm{nT}$ and standard deviation is $1.9 \mathrm{nT}$. They will be reduced if temperature variation is smaller, and it actually is at the OHP geomagnetic stations (again, about $5^{\circ} \mathrm{C}$ ) compared with that during the test measurement (about $20^{\circ} \mathrm{C}$ ).

If the performance of the temperature correction formula is as good as this example, once-a-year absolute measurements (i.e., baseline control) will make the observation with error of order a few nano-Teslas possible. 

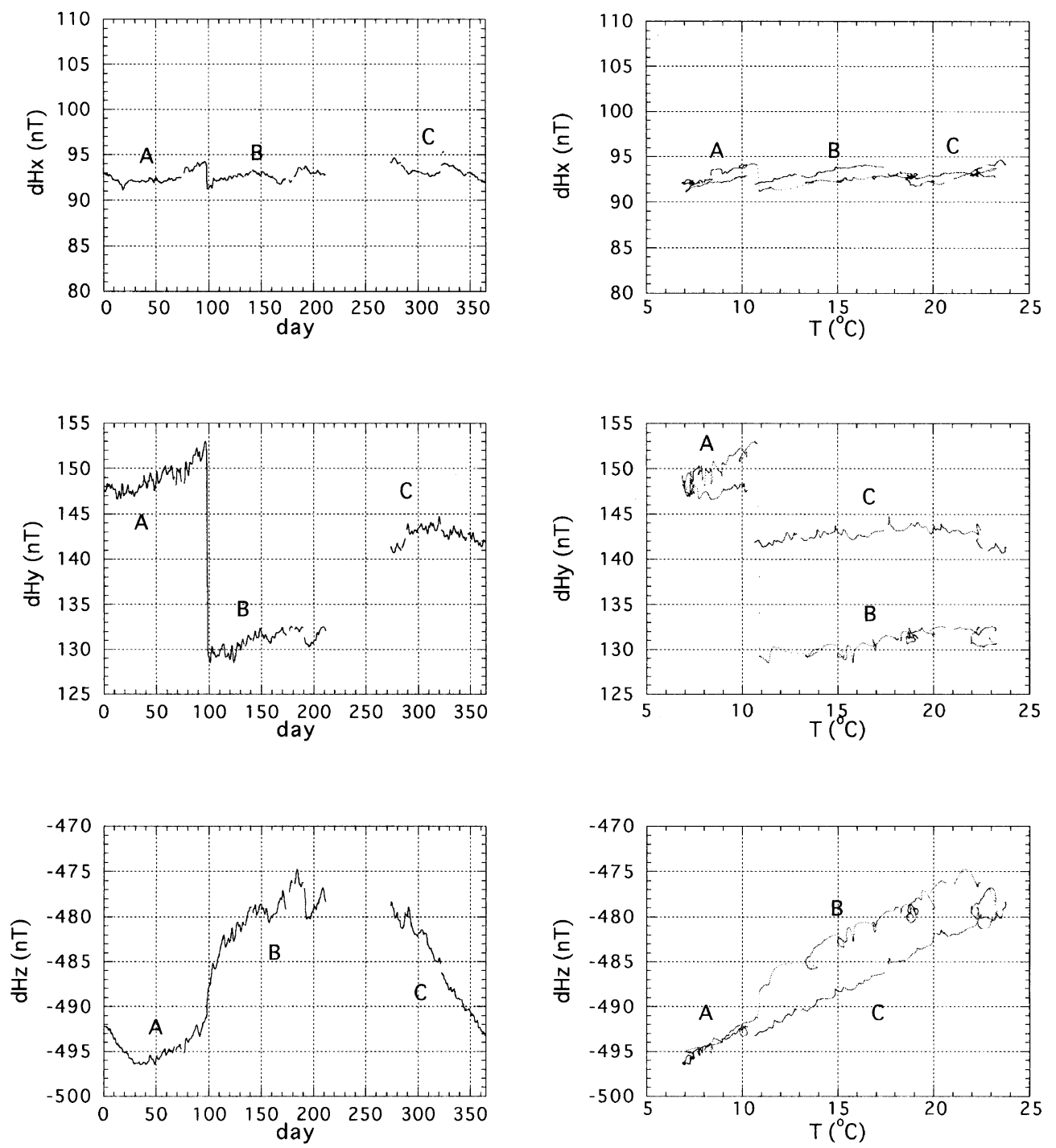

Fig. 7. Time series and $d H_{i}-T$ diagrams of the magnetic field data taken by OHP magnetometer $\# 4$ in 1998 . Occasional steps can be seen in the data. $A$, $B$, and $C$ indicate the same portions of the data, respectively.
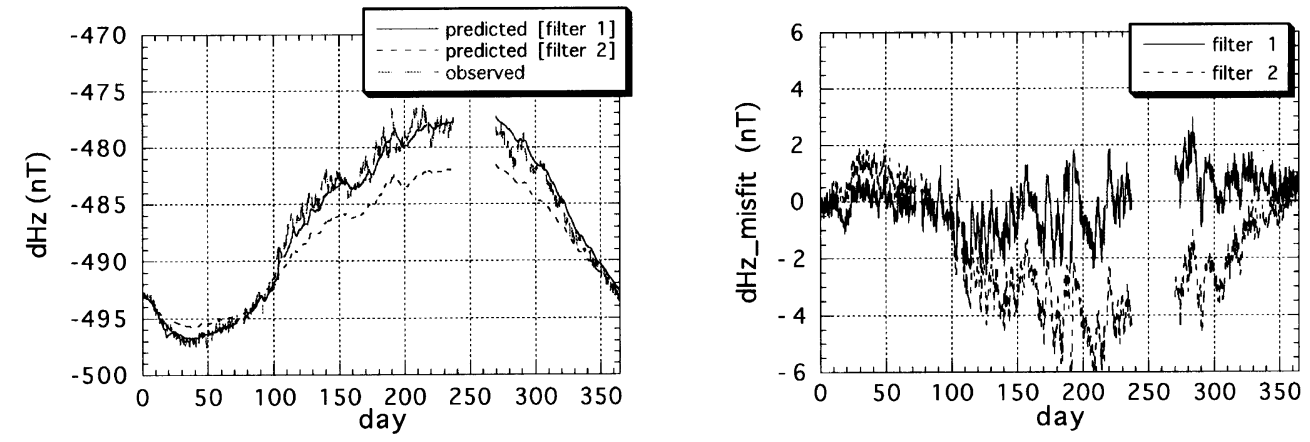

Fig. 8. Predicted $d H_{z}$ of \#4 during 1998. Day one for this plot is Jan. 1, 1998. Temperature correction filter 1 (Eq. (3)) and filter 2 (Eq. (4)) are used.

\section{Determination of Optimal Site Distribution}

The Pacific is one of the regions where the magnetic observatories are very few, i.e., not much information on the magnetic field in the region has been obtained. In the OHP it is planned to establish ten geomagnetic stations in the region.
Adding magnetic field data taken at these stations to geomagnetic field databases will improve global geomagnetic field models, and also the new information will facilitate the understanding of magnetic field distribution and variations in the area. For example, secular variation is believed to be low 
Table 4. Forty-seven permanent stations chosen by Schultz and Larsen (1987).

\begin{tabular}{|c|c|c|c|c|c|c|c|}
\hline Code & Name & Latitude & Longitude & Code & Name & Latitude & Longitude \\
\hline $\mathrm{ABK}$ & Abisko & 68.36 & 359.61 & MMB & Memanbetsu & 43.91 & 144.19 \\
\hline AAE & Addis Ababa & 9.03 & 38.76 & MUT & Muntinlupa & 14.38 & 121.01 \\
\hline $\mathrm{ABG}$ & Alibag & 18.64 & 72.87 & PAG & Panagyurishte & 42.51 & 24.18 \\
\hline ALM & Almeria & 36.85 & 357.54 & PIL & Pilar & -31.67 & 296.12 \\
\hline API & Apia & -13.81 & 188.22 & PMG & Port Moresby & -9.41 & 147.15 \\
\hline BLC & Baker Lake & 64.33 & 263.97 & RES & Resolute Bay & 74.70 & 265.10 \\
\hline $\mathrm{BNG}$ & Bangui & 4.44 & 18.56 & RSV & Rude Skov & 55.84 & 12.46 \\
\hline $\mathrm{BOU}$ & Boulder & 40.14 & 254.76 & SJG & San Juan & 18.50 & 293.88 \\
\hline DOB & Dourbes & 62.08 & 9.10 & SIT & Sitka & 57.05 & 224.06 \\
\hline ESK & Eskdalemuir & 55.32 & 356.80 & SOD & Sodankyla & 67.37 & 26.64 \\
\hline GDH & Godhavn & 69.24 & 306.48 & TNG & Tangerang & -6.17 & 106.63 \\
\hline HER & Hermanus & -34.42 & 19.22 & TKT & Tashkent & 41.33 & 69.30 \\
\hline $\mathrm{HON}$ & Honolulu & 21.32 & 201.94 & TEH & Tehran & 35.74 & 51.38 \\
\hline HUA & Huancayo & -12.04 & 284.66 & TEN & Tenerife & 28.48 & 343.72 \\
\hline IRT & Irkutsk & 52.27 & 104.27 & THL & Thule & 77.48 & 290.83 \\
\hline KAK & Kakioka & 36.23 & 140.19 & TIK & Tixic Bay & 71.58 & 129.00 \\
\hline KNY & Kanoya & 31.42 & 130.88 & TUC & Tucson & 32.25 & 249.17 \\
\hline KGL & Kerguelen & -49.35 & 70.20 & VAL & Valentia & 51.93 & 349.75 \\
\hline KIV & Kiev & 50.72 & 30.30 & VSS & Vassouras & -22.40 & 316.35 \\
\hline KOD & Kodaikanal & 10.23 & 77.46 & VIC & Victoria & 48.52 & 236.58 \\
\hline LRV & Leirvogur & 64.18 & 338.30 & WNG & Wingst & 53.74 & 9.07 \\
\hline LER & Lerwick & 60.13 & 358.82 & WIT & Witteveen & 52.81 & 6.67 \\
\hline LOV & Lovo & 59.34 & 17.83 & & & & \\
\hline MBO & M Bour & 14.39 & 343.40 & & & & \\
\hline MEA & Meanook & 54.62 & 246.67 & & & & \\
\hline
\end{tabular}

in the area (see, e.g., Bloxham and Gubbins, 1985). Magnetic field data from newly added stations will enable us to discuss shorter time-scale scale secular variations (decadal variations), which may not be as low as longer time-scale variations. Also, the data may be able to confirm the existence of the Pacific dipole window (e.g., Merrill et al., 1996) at present.

Global geomagnetic field is usually represented by a spherical harmonic expansion of scaler potential $V$ of the magnetic field $\mathbf{B}$,

$$
\mathbf{B}(r, \theta, \phi)=-\nabla V(r, \theta, \phi), \quad r \geq a_{\mathrm{E}},
$$

$$
\begin{aligned}
& V(r, \theta, \phi) \\
& =a_{\mathrm{E}} \sum_{n=1}^{N} \sum_{m=0}^{n}\left[\left[g_{n}^{m} \cos m \phi+h_{n}^{m} \sin m \phi\right]\left(\frac{a_{\mathrm{E}}}{r}\right)^{n+1}\right. \\
& \left.+\left[q_{n}^{m} \cos m \phi+s_{n}^{m} \sin m \phi\right]\left(\frac{r}{a_{\mathrm{E}}}\right)^{n}\right] P_{n}^{m}(\cos \theta)
\end{aligned}
$$

where $(r, \theta, \phi)$ is standard spherical coordinate, $P_{n}^{m}(\cos \theta)$ is the Schmidt normalized Legendre function, $a_{\mathrm{E}}$ is the radius of the Earth, and $g_{n}^{m}, h_{n}^{m}, q_{n}^{m}$, and $s_{n}^{m}$, are the Gauss coefficients (see e.g., Langel, 1987). $N$ is number of truncation of degree $n$ of the expansion, and $N=4$ is taken in the present case. It is expected that this truncation degree is large enough to represent semi-global features of the geomagnetic field in the Pacific although smaller scale structures cannot be reproduced.

The Gauss coefficients will be calculated by the magnetic field data from the OHP geomagnetic stations together with those from existing permanent geomagnetic observatories in the future. One of the lists of permanent observatories is given in Langel (1987), together with years of operation. The data from those observatories are expected to be of good quality; the absolute accuracy is of order $10 \mathrm{nT}$ or less and data gaps are minimal. Schultz and Larsen (1987) selected 47 permanent observatories (Table 4, open circles in Fig. 9) which continuously produce good data, and we will take them as the permanent observatory set here. It is evident that there 


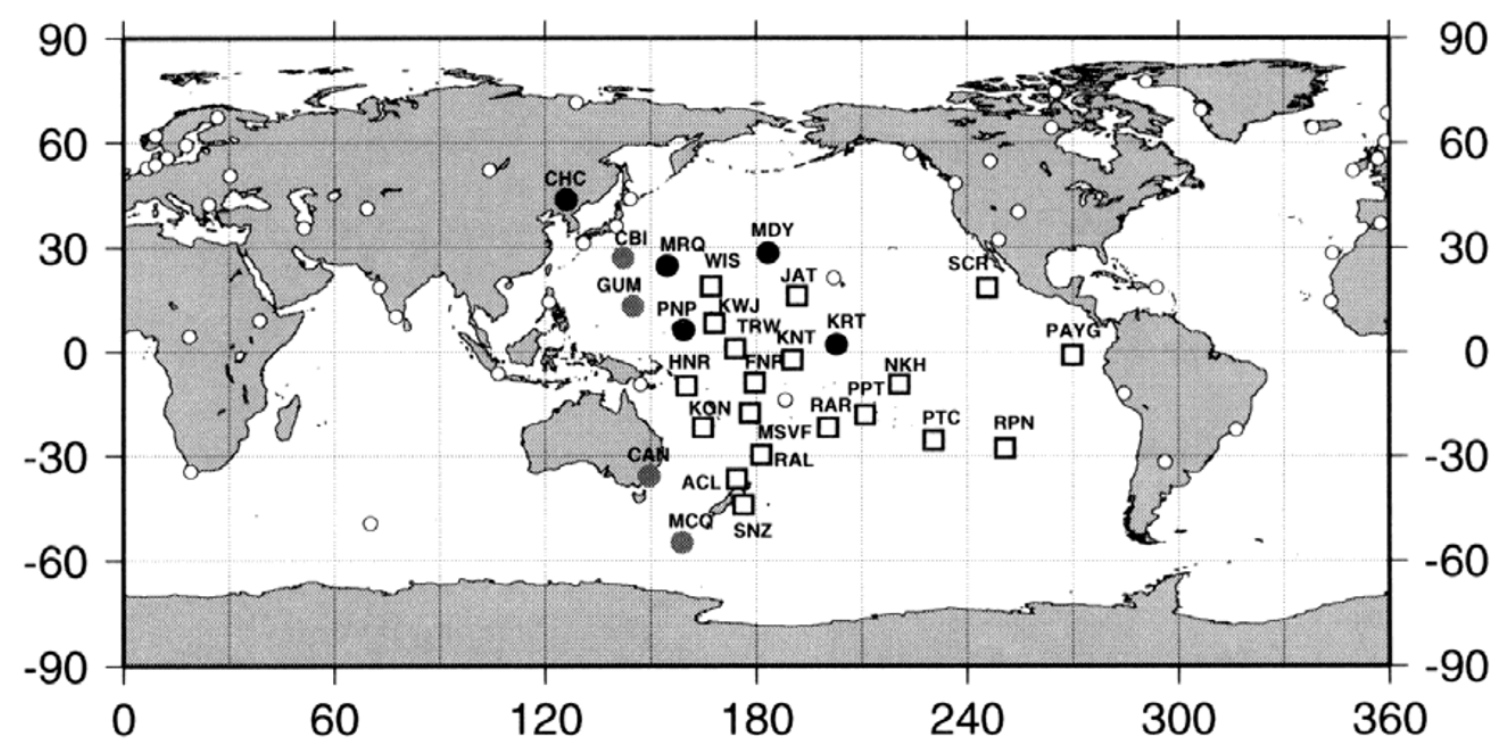

Fig. 9. Locations of permanent (open circle), semi-permanent (gray filled circles), planned (black filled circle) and candidate (square) stations.

are only few stations in the Pacific and southern hemisphere.

Candidate locations of OHP geomagnetic stations are selected at the locations where some kind of geophysical observation, such as geodetic, geomagnetic or seismological observation, has been or is going to be done. These places fulfill some of the requirements for the OHP magnetic stations: the places are accessible to us and colleagues both physically and politically, and necessary electric power and help by people, who take care of the magnetometer system including data collection, are available. Of course, it is obvious that the new stations should fill the large gaps of the permanent observatories in the Pacific. Twenty-eight locations are selected as the candidate places based on above mentioned requirements, see Table 5 and Fig. 9.

Baseline controlled data are known to be available in recent years at four of the selected 28 stations (Table 5, also see gray filled circles in Fig. 9) mostly due to the INTERMAGNET's effort, although they are not listed in Table 4. We will take these stations as semi-permanent station set in this study, and will exclude from the candidate places to install the OHP magnetometers. Five other stations out of the remaining candidate stations are either in plan or in operation. (OHP geomagnetic stations were already established at Ponape (Micronesia), Kiritimati (Christmas) Island (Kiribati) and Changchun (China). See Table 5, and also black filled circles in Fig. 9.) An OHP magnetometer was installed at Huancayo, Peru, which is one of the 47 permanent observatories but not publishing magnetic field data for a while. Now, the candidate stations are nineteen, as shown with squares in Fig. 9, and we will choose four locations from them.

Six candidate station sets were chosen to fill nicely the gaps of the geomagnetic observatories including semi-permanent and planned stations (Table 6, Fig. 10). (Note that we have not tried to choose all the possible combinations of selecting 4 stations out of 19 , but examined only 6 specific sets of locations. Therefore, some of the stations listed in the candidate stations are not considered at all further.) Station set $f$ extends to east the most. Other station sets, $a, b, c, d$, and $e$ all have the station NKH (Nukuhiva, Marquasas Islands) as the eastern-most station.

We are going to seek which distribution of the OHP geomagnetic stations is better to calculate more accurate Gauss coefficients together with the magnetic field data taken at existing observatories. Two simple tests were conducted to examine quantitatively if certain station distribution is suitable to calculate Gauss coefficients or not.

The first test is to compare the expected (predicted) misfit maps of magnetic field components for different station distributions when the magnetic field is expressed with the Gauss coefficients. Estimation of the predicted error is done based on the formulation in Langel (1987) and Langel et al. (1995). The magnetic field observation equation to be solved to calculate Gauss coefficients may be written as

$$
\hat{\mathbf{B}}=\mathcal{A} \mathbf{p}+\mathbf{e},
$$

where $\hat{\mathbf{B}}$ is a vector composed by observed magnetic field components at the observatories, $\mathbf{p}$ is the column vector of Gauss coefficients, $\mathcal{A}$ is an operator matrix which depends on the locations where magnetic field observations are made, and $\mathbf{e}$ is the vector of measurement errors. Formal least square solution to Eq. (7) may be written as

$$
\hat{\mathbf{p}}=\left(\mathcal{A}^{T} \mathcal{W} \mathcal{A}\right)^{-1} \mathcal{A}^{T} \mathcal{W} \hat{\mathbf{B}},
$$

where $\mathcal{W}$ is a diagonal weight matrix based on accuracy of magnetic field observations. Expected error of magnetic field components may be estimated by using the solution covariance matrix,

$$
\mathcal{V}_{p}=\left(\mathcal{A}^{T} \mathcal{W} \mathcal{A}\right)^{-1}
$$

If the geometric parameter vector for a linear component $B_{i}$ is $\mathbf{g}_{i}(\mathbf{r})$, i.e., if $B_{i}$ is written as

$$
B_{i}=\mathbf{p}^{T} \mathbf{g}_{i}(\mathbf{r}),
$$

estimated error for $B_{i}$ component at position $\mathbf{r}$ is

$$
\sigma_{B, i}(\mathbf{r})=\mathbf{g}_{i}(\mathbf{r})^{T} \mathcal{V}_{p} \mathbf{g}_{i}(\mathbf{r})
$$


Table 5. Candidate locations for OHP geomagnetic observations.

\begin{tabular}{|c|c|c|c|c|}
\hline Code & Name & Latitude & Longitude & Remark \\
\hline ACL & Auckland (NZ) & -36.55 & 174.47 & Candidate \\
\hline FNF & Funafuti (Tu) & -8.30 & 179.12 & stations \\
\hline HNR & Honiara (So) & -9.43 & 159.95 & \\
\hline JAT & Johnston Atoll & 16.45 & -169.42 & \\
\hline KNT & Kanton (Krb) & -2.50 & 188.60 & \\
\hline KON & Kone (NC) & -21.04 & 164.50 & \\
\hline KWJ & Kwajalein Atoll (Ms.I) & 9.15 & 167.30 & \\
\hline MSVF & Monasavu (Fi) & -17.73 & 178.05 & \\
\hline NKH & Nukuhiva (Mq.I) & -8.36 & -140.00 & \\
\hline PAYG & Puerto Ayora (SC) & -0.66 & -90.23 & \\
\hline PPT & Papeete (Th) & -17.32 & -149.34 & \\
\hline PTC & Pitcairn $(\mathrm{Pt})$ & -25.04 & -130.06 & \\
\hline RAL & Raoul Island (Krm) & -29.15 & 182.48 & \\
\hline RAR & Rarotonga $(\mathrm{CI})$ & -21.21 & -159.77 & \\
\hline RPN & Rapa Nui (EI) & -27.13 & -109.33 & \\
\hline SCR & Socorro Islands (Mex) & 18.9 & -115.00 & \\
\hline SNZ & South Karori (NZ) & -41.31 & 174.70 & \\
\hline TRW & Tarawa $(\mathrm{Kr})$ & 1.30 & 173.00 & \\
\hline WIS & Wake Islands (US) & 19.18 & 166.35 & \\
\hline $\mathrm{CHC}$ & Changchun $(\mathrm{CH})$ & 43.9 & 125.3 & Planned \\
\hline KRT & Kiritimati (Krb) & 2.00 & -157.30 & (or working) \\
\hline MDY & Midway & 28.21 & -177.33 & stations \\
\hline MRQ & Marcus (Minamitorishima) & 24.18 & 153.58 & \\
\hline PNP & Ponape & 6.9 & 158.10 & \\
\hline CAN & Canberra (AUS) & -35.30 & 149.00 & Semi- \\
\hline CBI & Chichijima & 27.15 & 142.30 & permanent \\
\hline GUM & Guam & 13.59 & 144.87 & stations \\
\hline MCQ & Macquarie Island & -54.50 & 158.96 & \\
\hline
\end{tabular}

CH: China, CI: Cook Islands, Ec: Equador, EI: Easter Islands (Chili), Fi: Fiji, Krm: Kermadic Islands, Krb: Kiribati, Mq: Marquasas Islands, Ms: Marshall Islands, NC: New Caledonia, PN: Papua New Guinea, Pt: Pitcairn Islands, SC: Santa Cruz Island (Galapagos Islands, Ecuador) So: Solomon Islands, Th: Tahiti, Tu: Tuvalu.

Table 6. Candidate station sets.

\begin{tabular}{ccccc}
\hline Station set & & & & \\
\hline$a$ & ACL & MSVF & NKH & RAR \\
$b$ & ACL & FNF & KON & NKH \\
$c$ & ACL & KON & NKH & RAR \\
$d$ & KON & NKH & RAL & RAR \\
$e$ & FNF & KON & NKH & RAR \\
$f$ & ACL & PAYG & PTC & RNP \\
\hline
\end{tabular}

Therefore, if a stations distribution and number of truncation $N$ of the spherical harmonic expansion (6) are given, possible errors at any location can be calculated by Eq. (11).

Estimated misfits of $Z$ component when $N=4$ for several station sets calculated by using Eq. (11) are shown in Fig. 11. Contour interval is $2 \mathrm{nT}$. Expected observation error at each station is assumed to be $1 \mathrm{nT}$, i.e., $\mathcal{W}$ in Eq. (9) is taken as the unit matrix. Expected error corresponding to $\alpha \mathrm{nT}$ observation error may be calculated just by multiplying $\alpha$ for the predicted error with $1 \mathrm{nT}$ observation error.

With only the permanent station set (47 stations in total) and permanent + semi-permanent station sets (51 stations), 


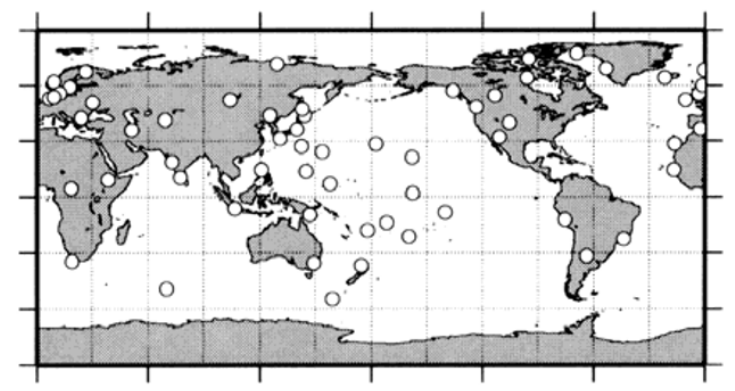

a)

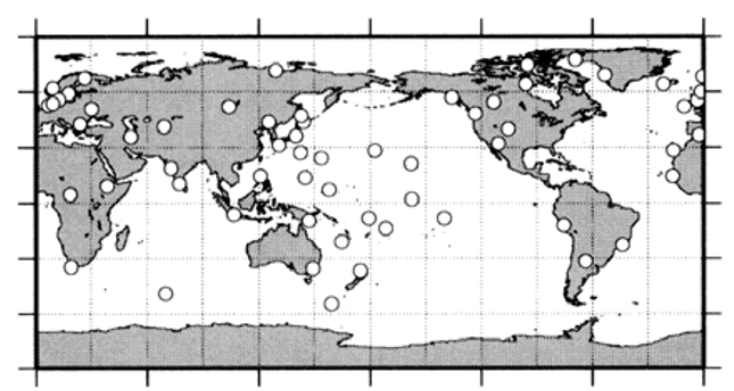

b)

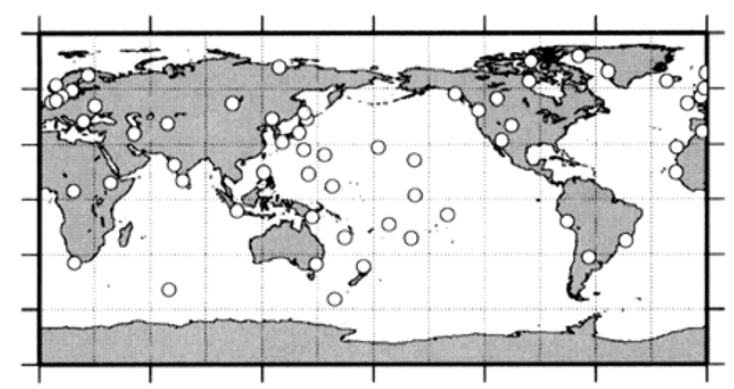

c)

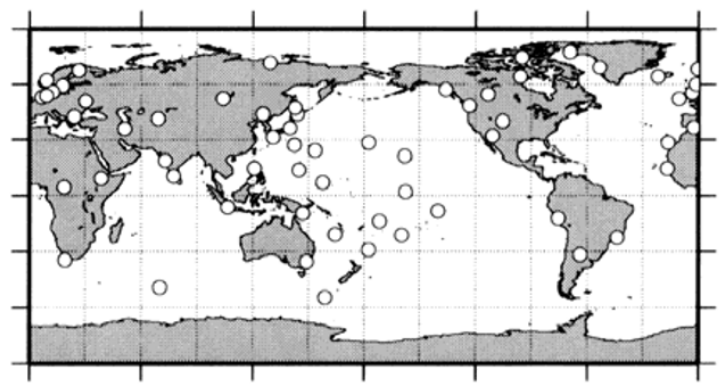

d)

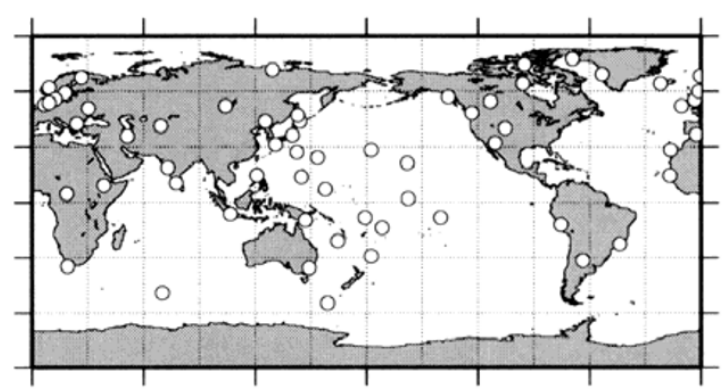

e)

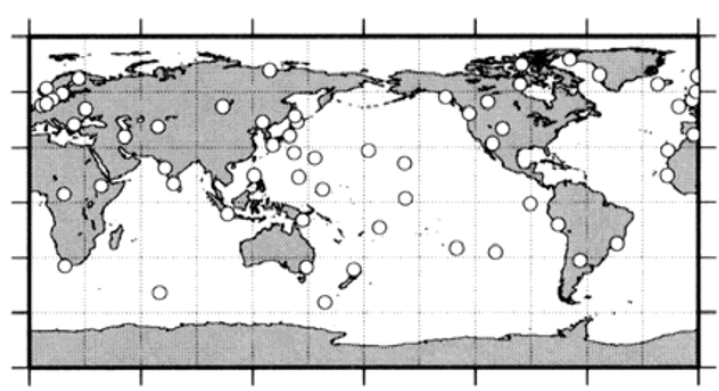

f)

Fig. 10. Six sets of candidate stations. (a)-(f) correspond to station set $a-f$ (Table 6), respectively.

there is a large high of misfit, which is about $40-50 \mathrm{nT}$, in the eastern Pacific (Fig. 11(A)). Adding only planned stations (56 stations in total) does not improve the expected errors very much: the estimate has misfit of about $20 \mathrm{nT}$ in the eastern Pacific (Fig. 11(B)). However, if the candidate station sets are included (60 stations in total), the situation is changed drastically. The high in the eastern Pacific is decreased to of order $5 \mathrm{nT}$ for station sets $a, b, c, d$, and $e$, and it's of order $2 \mathrm{nT}$ for station set $f$ (Figs. 11(a)-(f)). Note that the location of highs changes as seen in Fig. 11 if the candidate station sets are different. As a trial, all 75 stations are assumed to be working and distribution of expected misfit is calculated (Fig. 11(C)). No significant misfit more than $1 \mathrm{nT}$ can be seen in the Pacific (Fig. 11(C)). In contrast, a high remains in the Indian Ocean where no station is added.

In the second test, Gauss coefficients are actually calculated using artificial magnetic field data at supposed locations on the surface of the Earth. The artificial magnetic field data are calculated from supposed (i.e., known) Gauss coefficients so that direct comparison of the given and calculated Gauss coefficients can be made. To calculate the Gauss coefficients, a stochastic inversion code based on Gubbins and Bloxham (1985) is used. Because actual observations are not errorfree, artificial error may be added to the magnetic field data before the inversion. Proper comparison of the given and calculated Gauss coefficients, $\mathbf{p}_{\text {given }}$ and $\mathbf{p}_{\text {cal }}$, respectively, will indicate which distribution set is more appropriate for the calculation. The comparisons are made referring to rootmean-square fitting error $\left(\delta_{\text {rms }}\right)$ of Gauss coefficients (Schultz and Zhang (1994)),

$$
\delta_{\text {rms }}=\frac{\left\|\mathbf{p}_{\text {given }}-\mathbf{p}_{\text {cal }}\right\|}{\left\|\mathbf{p}_{\text {given }}\right\|},
$$

where $\|\cdot\|$ is the square norm.

To calculate the Gauss coefficients, we may use a set of two or more linearly independent magnetic field components as the data set such as $(X, Y, Z),(X, Z)$, or $(F, Z)$ components, where $X, Y, Z, F$ are geographical northward, east- 


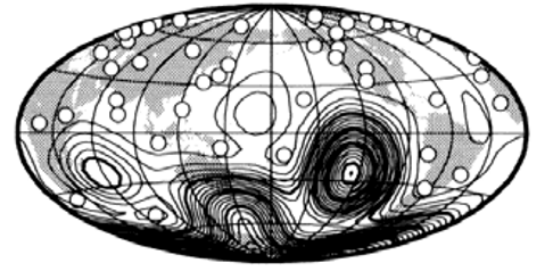

A)

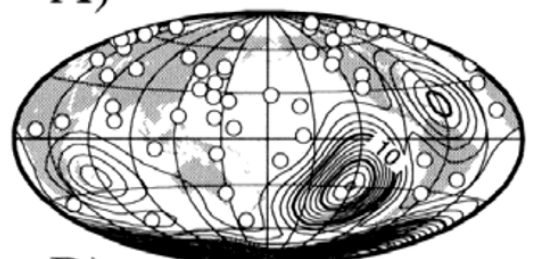

B)

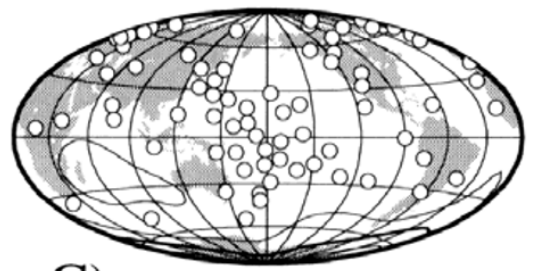

C)

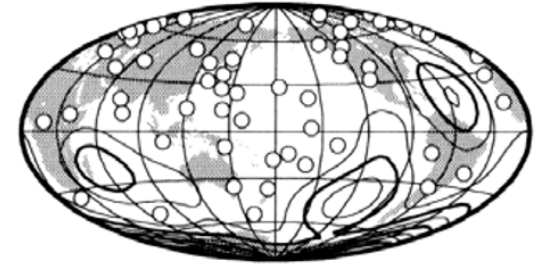

a)

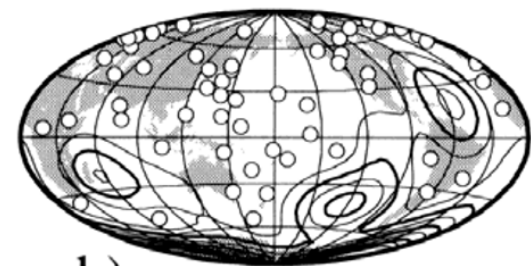

b)

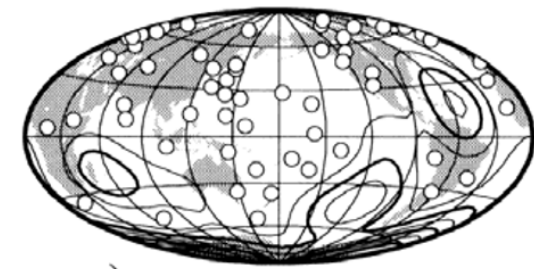

c)

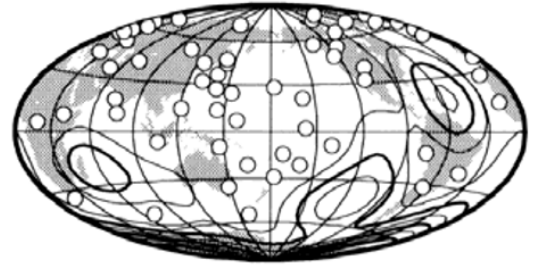

d)

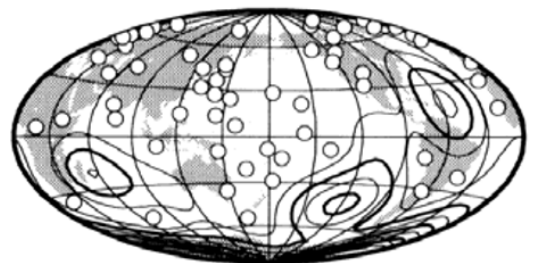

e)

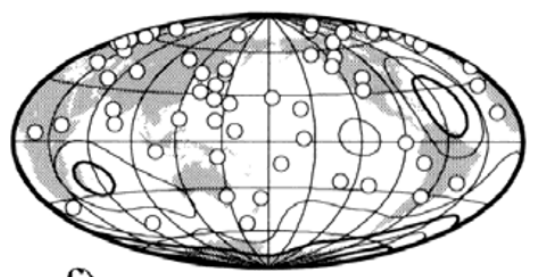

f)

Fig. 11. Estimated misfit of $Z$ component over the globe calculated using Eq. (6). Contour intervals are $2 \mathrm{nT}$ for all plots. (A) permanent station set (47 stations in total), (B) permanent, semi-permanent and planned station sets (56), (C) all possible stations (75), (a)-(f) with candidate station set $a-f$, respectively.

ward, vertically downward components, and total intensity, respectively. In the following, we will employ data sets composed by $(X, Z)$ and $(F, Z)$ when inverting the artificial data. Using $(X, Z)$ becomes a simple linear problem although inverting $(F, Z)$ require a nonlinear approach. It will be shown later that using $(X, Z)$ has slight advantage to determine the Gauss coefficients over using $(F, Z)$ when measurement error is the same. However, measurement of $F$, using proton or other scalar magnetometers, is simpler and absolutely more accurate than measuring and determining horizontal vector components. Therefore, in some cases, using $(F, Z)$ could be better than using $(X, Z)$.

For the direct calculation, the Gauss coefficients shown in Table $7(N=4)$, of which internal part from IGRF1995 (e.g., Barton et al., 1996) and external part assumed, are used. Random Gaussian errors of $2 \mathrm{nT}$ in standard deviation are added to the artificial magnetic field data to compare the case without measurement errors to see the stability of the calculated Gauss coefficients. For each station set, 30 different error distributions are tried and average of $\delta_{\text {rms }}$ 's are calculated.

Changes of $\delta_{\text {rms }}$ by increasing the number of stations both when measurement error is 0 and $2 \mathrm{nT}$ are shown in Fig. 12. With no error, large improvement, i.e., reduction of $\delta_{\text {rms }}$ is seen when number of stations is changed from 47 to 60 for both $(X, Z)$ and $(F, Z)$ cases. Note that estimated machine accuracy is of order $10^{-6}$. The $\delta_{\text {rms }}$ still decreases with increasing the number of stations even when $2 \mathrm{nT}$ error is added. Values of $\delta_{\text {rms }}$ for candidate station sets with $2 \mathrm{nT}$ errors are listed in Table 8 . The differences may be slight but the $\delta_{\text {rms }}$
Table 7. Given Gauss coefficients for test calculations.

\begin{tabular}{rrrcrc}
\hline$n$ & $m$ & \multicolumn{1}{c}{$g_{n}^{m}$} & $h_{n}^{m}$ & $q_{n}^{m}$ & $s_{n}^{m}$ \\
\hline 1 & 0 & -29682 & - & 100 & - \\
1 & 1 & -1789 & 5318 & 35 & 25 \\
2 & 0 & -2197 & - & 5 & - \\
2 & 1 & 3074 & -2356 & 0 & 0 \\
2 & 2 & 1685 & -425 & 0 & 0 \\
3 & 0 & 1329 & - & 0 & - \\
3 & 1 & -2268 & -263 & 0 & 0 \\
3 & 2 & 1249 & 302 & 0 & 0 \\
3 & 3 & 769 & -406 & 0 & 0 \\
4 & 0 & 941 & - & 0 & - \\
4 & 1 & 782 & 262 & 0 & 0 \\
4 & 2 & 291 & -232 & 0 & 0 \\
4 & 3 & -421 & 98 & 0 & 0 \\
4 & 4 & 116 & -301 & 0 & 0 \\
\hline
\end{tabular}

is the smallest for station set $f$ with either $(X, Z)$ or $(F, Z)$. The misfit is always smaller when $(X, Z)$ is used than when $(F, Z)$ is used due to the accuracy of algorithm employed for the two calculations.

The best distributions within the 6 candidate station sets is 


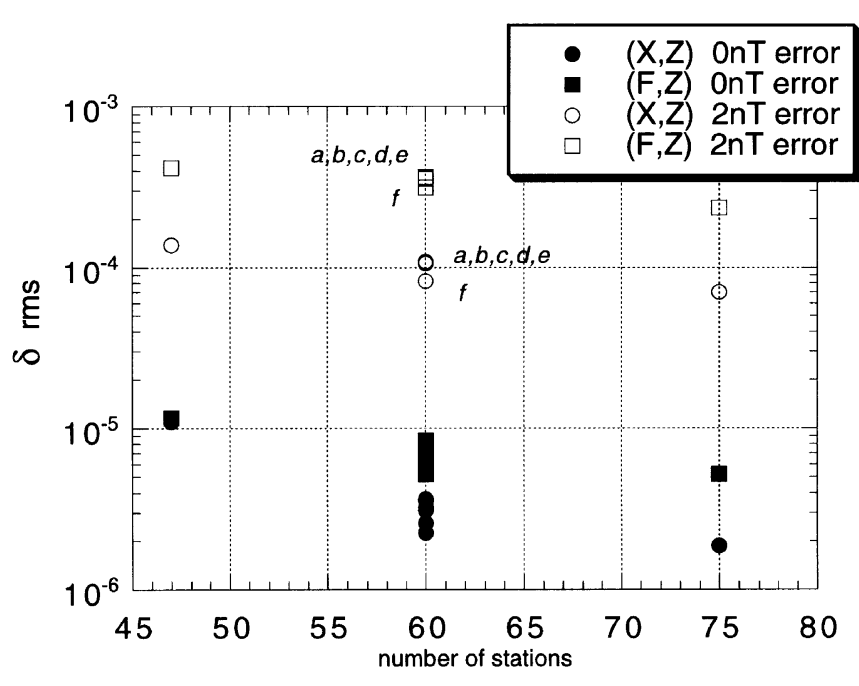

Fig. 12. $\delta_{\text {rms }}$ for the Gauss coefficients calculated by $(X, Z)$ and $(F, Z)$ with 0 and $2 \mathrm{nT}$ Gaussian errors. $\delta_{\text {rms }}$ for 60 stations crusterd into to two groups when measurement error is $2 \mathrm{nT}$ either $(X, Z)$ or $(F, Z)$ is used for calculations. For both cases, $\delta_{\text {rms }}$ for station set $f$ is the smallest. $\delta_{\text {rms }}$ for the other station sets are almost the same (see Table 8).

Table 8. $\quad \delta_{\text {rms }}$ calculated with candidate station sets when $2 \mathrm{nT}$ standard deviation errors are added.

\begin{tabular}{ccc}
\hline Station set & $(X, Z)$ & $(F, Z)$ \\
\hline$a$ & $1.07 \times 10^{-4}$ & $3.56 \times 10^{-4}$ \\
$b$ & $1.06 \times 10^{-4}$ & $3.63 \times 10^{-4}$ \\
$c$ & $1.07 \times 10^{-4}$ & $3.61 \times 10^{-4}$ \\
$d$ & $1.08 \times 10^{-4}$ & $3.56 \times 10^{-4}$ \\
$e$ & $1.09 \times 10^{-4}$ & $3.63 \times 10^{-4}$ \\
$f$ & $8.22 \times 10^{-5}$ & $3.13 \times 10^{-4}$ \\
\hline
\end{tabular}

$f$, but again the others are not very different. Summarizing the results, we may conclude that the accuracy is improved by noticeable amount with any of the candidate sets. Therefore, contribution of the OHP geomagnetic network is obvious irrespective of final design of the station distribution. If any other project starts geomagnetic observations at these sites, the station set may be any of the remaining 5 station sets.

\section{Summary and Discussion}

This paper described the instrumental design and performance of the magnetometer system used by the Ocean Hemisphere Network Project (OHP), and also discussed expected improvement of the geomagnetic field models when such an observation network is established.

In the earlier sections, it was shown that temperature change of the sensor unit is the major cause of fictitious magnetic field variations obtained by three-component fluxgate magnetometers. Temperature corrections for measured magnetic field components are necessary to sustain the accuracy of the observations. Test observations to study the temperature dependence of the magnetic field components measured by the OHP magnetometers were conducted at KMO before their actual deployments in the Pacific area. Time series analyses of thus obtained experimental data with reference to the site-definite observatory data revealed that the temperature dependence of each sensor unit can be expressed by a simple prediction filter composed of a pair of coefficients. For most of the fluxgate sensors tested, it was found that the obtained coefficients enable the correction of temperature effects with an accuracy of several nT for a typical time interval of 1 year. Such a temperature dependence is supposed to be proportional to the value of the compensation field of each axis (Trigg et al., 1971). This indicates that each observation will have a long-term accuracy of several $\mathrm{nT} / \mathrm{yr}$ after installed at each site of different bias value in the Pacific, although the proportionality is not examined for the present magnetometer.

As mentioned in the earlier section, absolute geomagnetic measurements are/will be repeated every year at each OHP geomagnetic site. Each absolute measurement gives absolute values of the baselines, and the observation accuracy at each site depends only on the amount of drift during the interval between the absolute measurements.

It is possible for the present observatory design to keep an overall accuracy of three-components at each site typically less than several nano Teslas and for the worst case about 10 $\mathrm{nT}$. In case of studying geomagnetic variations of decadal time scales, signal amplitude is estimated as about $100 \mathrm{nT}$ for the axial dipole and 30-50 nT for dominant higher terms (Yokoyama and Yukutake, 1991). With repeated absolute measurements every year, thus, the OHP geomagnetic observatory will be able to dramatically improve the spatial and temporal resolution for detecting decadal geomagnetic variations in the Pacific area.

The good expected performance of the OHP magnetometers is partly due to the instrumental design of the fluxgate magnetometer. Use of gimbals system to mount the fluxgate sensors can remove the effect of basement tilt for a possible baseline drift. Installing the sensor container in the ground reduces temperature variation of the sensor unit. Not only the amplitude of the temperature variation is reduced, the short time scale variation is cut by heat insulation of the soil. This makes three component variation data at shorter periods ( $<$ several days) highly accurate, which will improve the resolution of studying the electrical conductivity structure in the mantle.

The same concept may be applied to a design of an ocean bottom geomagnetic observatory. Since ordinary absolute measurement can not be done on the seafloor, both baseline values of 3-components and their drift rates are unknown in this case. One necessary approach is to calibrate the absolute direction of orientation of each axis either by a mechanical gyro system or by a combination of acoustic and optical positioning from the surface ship to the bottom observatory (Chave et al., 1995). However, observed data will be useless for studies of long-term geomagnetic variations unless the baseline drift is reduced to a tolerable level. Temperature effects may be less important in this case because of the stable condition at the bottom of deep ocean. However, tilting effect will be enormous because of the presence of soft sediment on the seafloor. Use of gimbals is the easiest way to solve this problem. This also has an advantage that the direction of the vertical axis of a magnetometer is accurate. Simple 
model calculations in the later section showed that addition of observation sites in which combination of $H_{z}$ and $F$ of the geomagnetic field will sufficiently improve the field model quality. The implications obtained in this study greatly reduce the technological difficulties in developing an actually useful seafloor geomagnetic observatory (Toh et al., 1998).

Six candidate station sets are tested to seek the suitable OHP geomagnetic station distribution for the calculations of Gauss coefficients. It turned out that all station sets examined will be able to provide greatly improved Gauss coefficients. The distribution of the OHP geomagnetic stations are not finalized yet at present. However, the tests in Section 4 will be conducted to confirm that actual distribution of the OHP geomagnetic stations are as good as the candidate station sets discussed in the section.

The Gauss coefficients will be used to discuss global scale geomagnetic field and its variations. An interesting topic is the secular variations in the Pacific, especially in short timescales. Low secular variation compared with the other regions is reported for somewhat longer time-scales (Bloxham and Gubbins, 1985) and this may be explained by the dynamics of the outer core and interactions between the core and mantle. It would be interesting to compare if the short time-scale variations are as low as that expected form longer time-scale variations. The information will be used to constrain those processes and also the electrical conductivity of the mantle.

Acknowledgments. The definite magnetic field data at Kakioka was provided by Kakioka Magnetic Observatory, Japan Meteorological Agency. Mr. T. Ohwada and Mr. F. Fukui are acknowledged for their assistance for test observation using OHP magnetometers at KMO. The authors would like to thank two referees, Dr. M. Everett and Dr. M. Matsushima, for the valuable comments to improve this paper. This work was partly supported by Grant-in-Aid for Scientific Research (C) (\#08640523) by Ministry of Education, Science, Sports and Culture.

\section{References}

Achache, J., J. L. LeMouël, and V. Courtillot, Long-period geomagnetic variations and mantle conductivity: an inversion using Bailey's method, Geophys. J. R. astr. Soc., 65, 579-601, 1981.

Banks, R. J., Geomagnetic variations and the electrical conductivity of the upper mantle, Geophys. J. R. astr. Soc., 17, 457-487, 1969.

Barton, C. E., R. T. Baldwin, D. R. Barraclough, S. Bushati, M. Chiappini,
Y. Cohen, R. Coleman, G. Hulot, P. Kotzé, V. P. Golovkov, A. Jackson, R. A. Langel, F. J. Lowes, D. J. McKnight, S. Macmillan, L. R. Newitt, N. W. Peddie, J. M. Quinn, and T. J. Sabaka, International Geomagnetic Reference Field, 1995 revision presented by IAGA Division V, Working Group 8, Phys. Earth Planet. Inter, 97, 23-26, 1996.

Bloxham, J. and D. Gubbins, The secular variation of Earth's magnetic field, Nature, 317, 777-781, 1985.

Chave, A. D., A. W. Green, Jr., R. L. Evans, J. H. Filloux, L. K. Law, R. A. Petitt, Jr., J. L. Rasson, A. Schultz, F. N. Spiess, P. Tarits, M. Tivey, and S. C. Webb, Report of a workshop on technical approaches to construction of a seafloor geomagnetic observatory, Woods Hole Oceanographic Inst. Tech. Rep., WHOI-95-12, 43 pp., 1995.

Forbes, A. J., General Instrumentation, in Geomagnetism vol. 1, edited by J. Jacobs, pp. 51-142, Academic Press, 1987.

Fukao, Y., The Ocean Hemisphere Network Project, Proc. OHP International Symp., 9, 1997.

Gubbins, D. and J. Bloxham, Geomagnetic field analysis-III. Magnetic fields on the core-mantle boundary, Geophys. J. R. astr. Soc., 80, 695-713, 1985

INTERMAGNET, INTERMAGNET Technical Reference Manual, 73 pp., 1994.

Langel, R. A., The main field, in Geomagnetism vol. 1, edited by J. Jacobs, pp. 249-512, Academic Press, 1987.

Langel, R. A., R. T. Baldwin, and A. W. Green, Toward and improved distribution of magnetic observatories for modeling of the main geomagnetic field and its temporal change, J. Geomag. Geoelectr., 47, 475-508, 1995.

Merrill, R. T., M. W. McElhinny, and P. L. McFadden, The Magnetic Field of the Earth, 531 pp., Academic Press, 1996.

Schultz, A. and J. C. Larsen, On the electrical conductivity of the midmantle-I. Calculation of equivalent scalar magnetotelluric response functions, Geophys. J. R. astr. Soc., 88, 733-761, 1987.

Schultz, A. and T. S. Zhang, Regularized spherical harmonic analysis and the 3-D electromagnetic response of the Earth, Geophys. J. Int., 116, 141-156, 1994.

Shimizu, H., T. Koyama, and H. Utada, An observational constraint on the strength of the toroidal magnetic field at the CMB by time variations of submarine cable voltages, Geophys. Res. Lett., 25, 4023-4026, 1998.

Toh, H., T. Goto, and Y. Hamano, A new seafloor electromagnetic station with an Overhauser magnetometer, a magnetotelluric variograph and an acoustic telemetry modem, Earth Planets Space, 50, 895-904, 1998.

Trigg, D. F., P. H. Serson, and P. A. Camfield, A solid state electrical recording magnetometer, Pub. Earth Phys. Branch (Geol. Surv. Canda), 41, 5, 1971

Yokoyama, Y. and T. Yukutake, Sixty year variation in a time series of the geomagnetic Gauss coefficients between 1910 and 1983, J. Geomag. Geoelectr., 43, 563-584, 1991.

Yumoto, K. and the $210^{\circ} \mathrm{MM}$ Magnetic Observation Group, The STEP $210^{\circ}$ magnetic meridian network project, J. Geomag. Geoelectr., 48, 12971309,1996

H. Shimizu (e-mail: shimizu@eri.u-tokyo.ac.jp) and H. Utada 